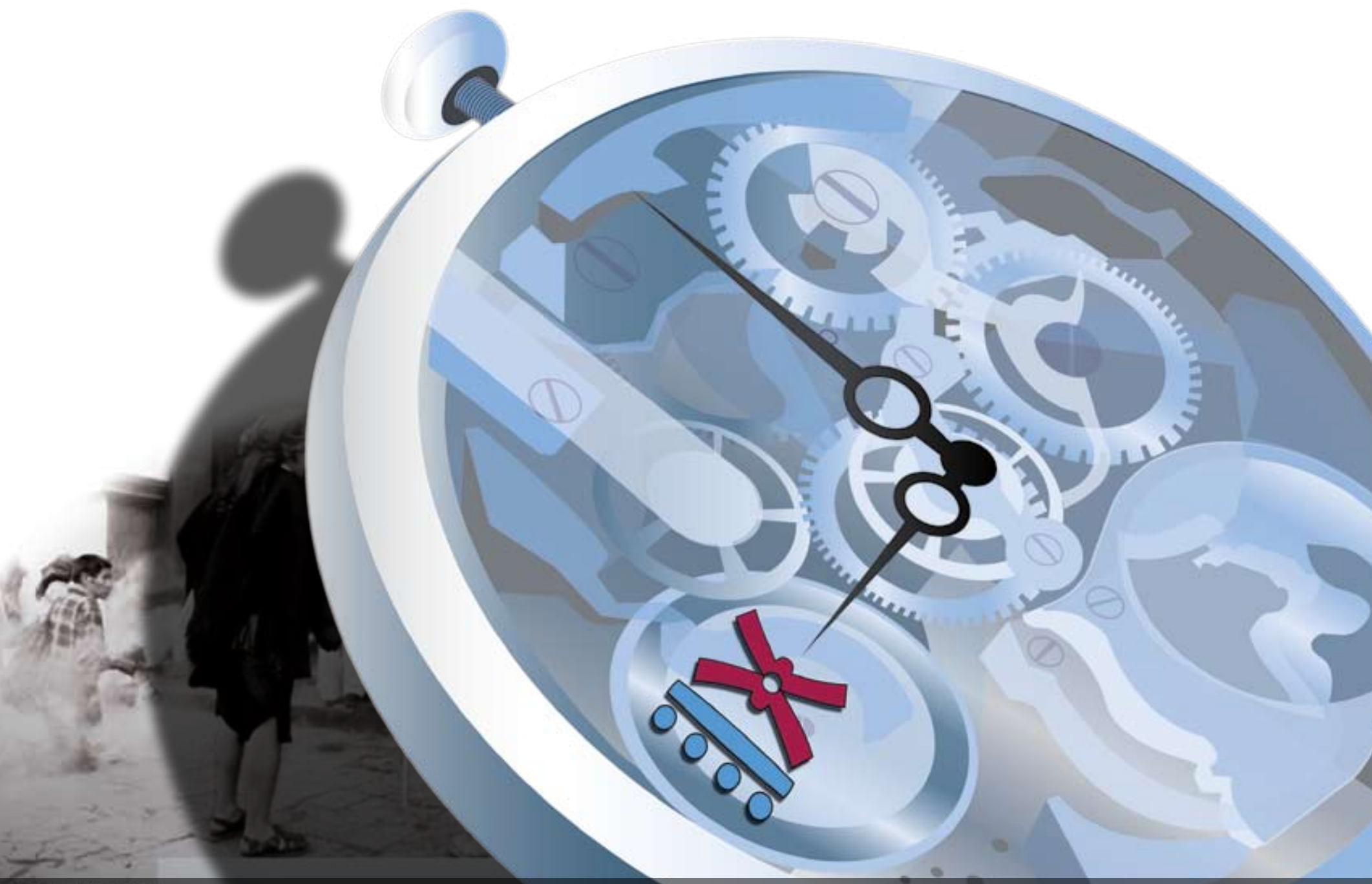

O $9^{\circ}$ C O N G R E O 2. CENTROAMERICANO DE HISTORIA

ISSN 1409-469X

Fecha de recepción: 15 de mayo 2008 Fecha de aceptación: 30 de mayo 2008

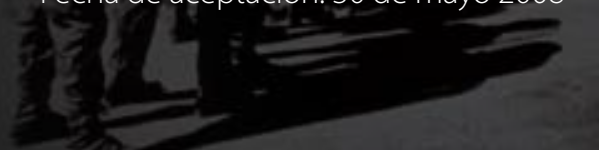

La Nueva Guatemala, el espíritu ilustrado en el Reino de Guatemala e hipótesis sobre algunas de sus consecuencias

Miembros del Consejo Editorial:

Dr. Ronny Viales, Dr. Juan José Marín

Editores Técnicos:

Allan Fonseca, Andrés Cruz, Gabriela Soto

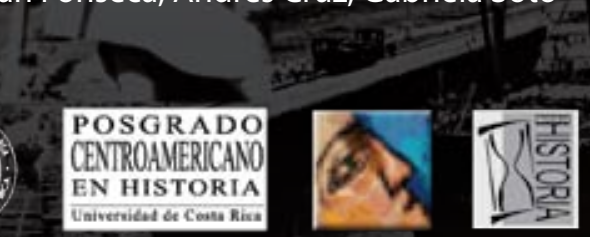




\title{
La Nueva Guatemala, el espíritu ilustrado en el Reino de Guatemala e hipótesis sobre algunas de sus consecuencias
}

\author{
Jorge Luján Muñoz \\ Universidad del Valle de Guatemala \\ Titular, Cátedra J. Joaquín Pardo \\ Departamento de Historia
}

\section{Introducción}

La ponencia se puede describir como un resumen acerca de la Ilustración (en sentido general y aplicado a Hispanoamérica) con especial énfasis en el Reino de Guatemala y la capital del reino, para finalmente plantear, con el propósito de su discusión y comentario en la Mesa Colonial, una hipótesis sobre las consecuencias que tuvo, a mediano y largo plazo, en el desarrollo de la historia guatemalteca y centroamericana, y quizas española e hispanoamericana.

Comienzo referiéndome a la asociación de las reformas borbónicas con la Ilustración en el caso español, centrándome en lo americano. Hago mención específica, por sus proyecciones, del resultado no previsto que provocaron, al desplazar a los criollos de espacios de poder en los que habían venido participando. Discuto, asimismo, lo que he llamado "el sentido urbano del sistema colonial español". A continuación me refiero a las fundaciones urbanas en el reino y al caso de la destrucción y el traslado de la capital, para pasar luego a tratar brevemente de las principales manifestaciones ilustradas en la Nueva Guatemala. Cierro el ensayo planteando una hipótesis acerca de los efectos que tuvo la Ilustración en Hispanoamérica (y probablemente en España y otros países europeos), a mediano y largo plazo, como resultado del creciente rompimiento de la relativa unidad que había existido previamente dentro del sector urbano educado. Se produjo la polarización en dos tendencias o partidos principales, que se hicieron irreconciliables: tradicionalistas (los posteriores conservadores) y reformistas (los liberales). Se trató de un efecto inesperado que provocó el espíritu ilustrado y que tuvo graves consecuencias en la vida independiente, ya que esa polarización se acentuó después de la emancipación, dando lugar a guerras civiles, expulsiones del país y otras medidas extremas e intransigentes. Tengo especial interés en recibir los comentarios de los colegas acerca de esta hipótesis.

\section{Conceptos y antecedentes}

Cualquier autor que escriba sobre este tema se enfrenta con dos problemas iniciales: el del ámbito temporal y el de la terminología. Conviene aclarar ambos de inmediato. El primero se refiere a la época en que se inició el movimiento ilustrado en Hispanoamérica y cuándo finalizó, y el segundo, a cuáles son los vocablos correctos a usar y su sentido. Es usual decir que abarcó todo el siglo XVIII, al que se le llama "Siglo de las Luces". Sin embargo, al menos en el caso de España e Hispanoamérica, hay que tener en cuenta dos situaciones: que hubo un "retraso" de varias décadas en su comienzo con respecto a Europa occidental y que éste resultó poco definido, además de lento y conflictivo. Fue hasta la década de 1760 que se aprecia un mayor ritmo de cambios y reformas. En cuanto al cierre, así como hubo retraso en su arranque, también lo hubo en su término, que en América se prologa en los procesos emancipadores y los inicios de la vida independiente. 


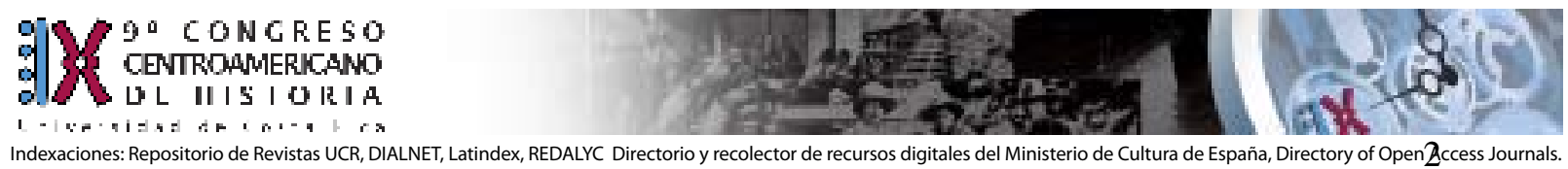

Indexaciones: Repositorio de Revistas UCR, DIALNET, Latindex, REDALYC Directorio y recolector de recursos digitales del Ministerio de Cultura de España, Directory of Open Zccess Journals.

Diálogos Revista Electrónica de Historia ISSN 1409-469X. Número especial 2008. Dirección web: http://historia.fcs.ucr.ac.cr/dialogos.htm

En la literatura histórica se habla no sólo de Ilustración sino de "iluminismo" y

"siglo o época de las luces”. Opino que lo más adecuado es utilizar el vocablo

Ilustración y no emplear (al menos en lengua española) los vocablos "iluminismo" e

"iluminación", porque tienen una connotación religiosa y se refieren a los seguidores de

la secta herética de los iluminados. ${ }^{1}$ Lo de "las luces" (Siécle des Lumières), mejor sólo emplearlo para señalar una de las características del movimiento.

Más que un conjunto de ideas definidas, la Ilustración implicaba una actitud, un método de pensamiento. El período se caracterizó por el optimismo de sus seguidores en cuanto al poder de la razón humana y a la necesidad de reorganizar o reformar a fondo la sociedad con base en los principios racionales. Ese optimismo se expresa claramente en el lema que se incorporó en el reverso del sello mayor de los Estados Unidos de América: “Novus Ordo Seclorum" ("Nuevo orden de los tiempos”), que por cierto no es un lema masónico. En Europa se dio con mayor fuerza en Alemania, Francia e Inglaterra. En España fue débil al principio y sólo se desarrolló con algún vigor cuando contó con el decidido apoyo oficial, durante el reinado de Carlos III, desde la estrategia del “despotismo ilustrado”. Además, los ilustrados españoles mantuvieron una actitud ambigua, casi temerosa, frente a la Iglesia católica, a fin de evitar cualquier denuncia inquisitorial.

Fue esencial su interés por estudiar la naturaleza y utilizarla para mejorar la vida humana. Asimismo, subrayó la importancia de la experiencia sensible como medio de conocimiento frente a la especulación racional. Combatió y se burló del fanatismo, la superstición, la mogigatería y la superchería. ${ }^{2}$ Promovió la tolerancia en lo religioso, lo intelectual y lo político. Volvió el humanismo (antropocéntrico) del Renacimiento y promovió la libertad (en el sentido de autonomía de la voluntad) y la capacidad de los seres humanos educados para "atreverse a conocer" o "atreverse a saber" (sapere aude), a fin de salir de su "culpable” y limitado estado de pupilo, como requisito necesario para alcanzar la libertad y, por lo tanto, la dignidad. En ese sentido hay que tener en cuenta la respuesta de Immanuel Kant a la pregunta “¿Qué es la Ilustración?”, en la que defendió el derecho a pensar por sí mismo y dejar de ser menores de edad. ${ }^{3}$ Es decir, tener la valentía y la decisión de servirse del entendimiento sin guía o control ajeno. Esas ideas promovieron un amplio debate ideológico en Europa y provocaron desconcierto en los sectores tradicionalistas. La reacción de las monarquías europeas fue tratar de controlar los procesos a través del llamado despotismo ilustrado.

Es evidente que muchos de los anteriores elementos o postulados no podían tener un campo fértil ni fácil en España, un país con una sola religión, en el que desde los Reyes Católicos no se toleraba otra. ${ }^{4}$ Además, la Iglesia católica no estaba dispuesta a ceder su papel hegemónico. Desde el siglo XVI era política de Estado la identificación entre gobierno y religión católica, con un minucioso control ideológico a través de la inquisición. Sin embargo, hay que reconocer que no sólo en España hubo desconcierto oficial y reacción en contra de las posturas ilustradas. En otras palabras, la Ilustración fue una corriente que generó reacciones en contra y desconfianza, que se manifestaron de muchas formas. La reacción contraria se reforzó después de los excesos de la Revolución Francesa.

\section{Cambios en la administración colonial española en el siglo XVIII}

Los borbones aplicaron en América las mismas políticas reformistas y centralizadoras que en la península, en el marco de la creciente ideología del Estado absoluto. Los medios usados en la política borbónica se centraron en la creación de nuevos organismos (que casi siempre coexistieron con los heredados de los Austrias). 


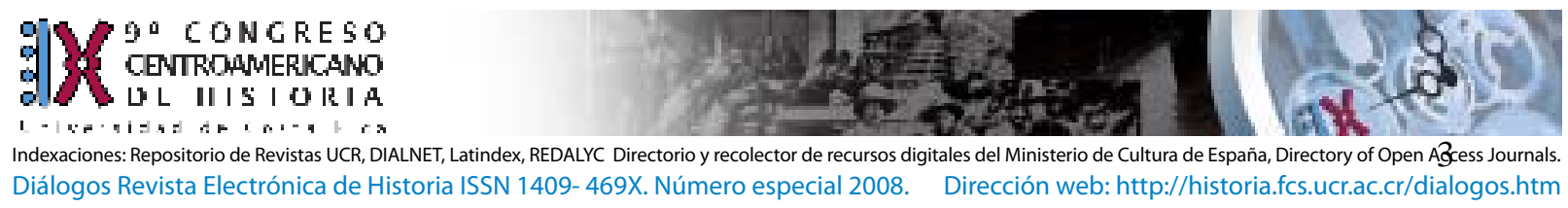

Tanto en España como en ultramar las más profundas transformaciones y de mayor proyección se dieron hasta en la segunda mitad del siglo XVIII, sobre todo a partir de 1764. En ello influyó la presencia de Carlos III en el trono y su preocupación por hacer más efectiva su relación con los terriotrios americanos tras la recuperación de La Habana.

Después de la Paz de Utrecht (1713-14) se creó (junto a otras cuatro) la Secretaría de Estado y del Despacho de Marina e Indias, que desplazó algunas de las funciones del Consejo de Indias, que después de 1717 se limitó casi únicamente a los aspectos judiciales. El concepto de secretaría de estado fue una importación borbónica, bien diferente del sistema de consejos, favorecido hasta entonces. La nueva secretaría fue una dependencia real que debía de dirigir, para las Indias, la hacienda, el comercio, la defensa y otras materias a fin de hacer más efectiva la administración y el gobierno. Casi simultáneamente se trasladó la Real Casa de Contratación de Sevilla a Cádiz (1717-18) y se creó un tercer virreinato, el de Nueva Granada (1717, suprimido en 1723 y restaurado definitivamente en 1739). En el aspecto comercial disminuyeron las tasas de importación o se derogaron del todo. Se crearon compañías privilegiadas regionales para llevar a cabo con exclusividad y preferencia (monopolios) el comercio con regiones específicas, como la Real Compañía Guipuzcoana de Caracas (con Venezuela), en 1728; la de la Habana, en 1740; la Real Compañía de Comercio para las Islas de Santo Domingo, Puerto Rico y la Margarita, de 1755, y la de Honduras en $1775 .^{5}$

La disputa americana entre británicos y españoles tuvo muchos momentos difíciles a lo largo del siglo XVIII. Los ejemplos más evidentes son la toma de Portobello, en 1739; varios ataques a Puerto Rico, el intento frustrado de capturar Cartagena de Indias (1741); la toma de La Habana (1762), durante la llamada Guerra de los Siete Años, que recobró España en la Paz de París de 1763. En 1797 se produjeron el ataque exitoso a la Isla de Trinidad (febrero) y el de la misma flota a San Juan en Puerto Rico (abril), que fracasó. Ese tipo de acciones culminaron en el Río de La Plata, con la toma de Buenos Aires en 1806, para ser rechazados 46 días después, y la toma de Montevideo el año siguiente, donde permanecieron algunos meses.

Durante el reinado de Carlos III (1759-1788) se activó el ritmo de los cambios, apoyado por un cuerpo de capaces ministros ilustrados. El programa de reformas incluyó una mayor restricción de las funciones del Consejo de Indias, la división de la Secretaría de Marina e Indias en dos separadas; así como la creación de un cuarto virreinato, el de La Plata (1776), que comprendía más o menos lo que hoy son Argentina, Uruguay, Paraguay y Bolivia (Alto Perú).

Un reajuste reformador importante se enfocó hacia la desregulación del comercio entre España y sus colonias o territorios de ultramar como se decía entonces, dentro de una mayor libertad de comercio, incluyendo el intercambio directo entre los diferentes reinos (autorizado entre 1770 y 80). También se suprimió temporalmente el sistema de flotas. Todo ello disminuyó costos, aumentó el número de navíos y rebajó las tarifas de carga, con el consiguiente aumento del comercio. Asimismo, se incrementó el combate al contrabando, con limitados resultados. Esto último requirió mejorar las defensas costeras y la apertura o modernización de puertos, pero ello fue insuficiente para detener el intercambio ilegal.

Un tema de constante preocupación fue incrementar los ingresos de la real hacienda y así poder no sólo obtener fondos destinados a la península, sino para financiar los gastos que implicaban las reformas en Indias. Entre los cambios efectuados con ese propósito estuvo el que la Corona asumiera la recaudación de algunos impuestos que se habían arrendado a los ayuntamientos (p.e. las alcabalas y el 


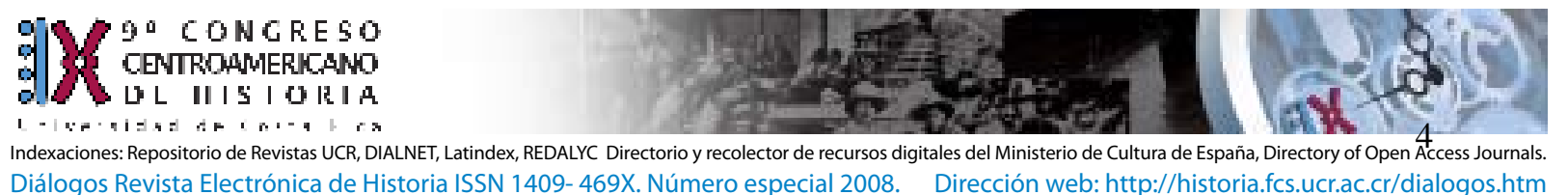

aguardiente). Asimismo, se estableció el estanco del tabaco, que provocó duros reajustes en el cultivo, que fueron impopulares por sus efectos depresivos en varias regiones. ${ }^{6}$

El reformismo en la administración colonial se produjo en un momento de relativa prosperidad general en Hispanoamérica, en el que aumentaba el intercambio comercial y crecía la población (sobre todo resultado del crecimiento natural y no de la inmigración española -que no se incrementó- o de población negra -que sí creció-). Sin que tuvieran un reflejo importante en la evolución demográfica, se llevaron a cabo, en diferentes momentos y regiones, proyectos de colonización con población española, básicamente de campesinos de Galicia y Canarias. Cualitativamente tuvo mucha proyección y efectos, en los sectores medios y altos, la llegada de jóvenes provenientes de las provincias vascas, que destacaron como comerciantes y empresarios en casi todas las colonias hispanoamericanas.

Las reformas borbónicas en América llegaron a su culminación con el establecimiento del sistema de intendencias, que ya se había aplicado en la península. Se inició con la de La Habana, en 1765-67 (inmediatamente después de la desocupación inglesa de 1763, que no llegó a durar un año). En la Nueva España se implantó como resultado de la visita de José de Gálvez a dicho virreinato (la cual se inició en 1764). Luego, ya bajo la Secretaria de Indias de José de Gálvez, se establecieron en 1776 en lo que hoy es Venezuela (Caracas, Cumaná, Margarita, Guayana y Maracaibo). Siguió La Plata, en 1778, dos años después de instaurado el virreinato. En 1782 se dictaron las Ordenanzas de Intendentes del Río de la Plata, pasando a ser la de Buenos Aires de “ejército y provincia” y las otras sólo de "provincia”. A continuación se aplicó el sistema en Perú, en 1784 (siguiendo las ordenanzas de La Plata con adaptaciones; la de Lima fue de "ejército y provincia” y las demás de "provincia”). Ese mismo año se establecieron en Filipinas, a la vez que se nombró intendente al Gobernador de Puerto Rico. Después se aplicó en el Reino de Guatemala (decidido en 1785 y puesto en ejecución el año siguiente), comenzando por El Salvador y siguiendo con Ciudad Real (Chiapas), León (Nicaragua) y Comayagua (Honduras), a lo largo de 1786; no se establecieron en Guatemala, donde residía el Presidente de la Audiencia y Capitán General, que tuvo la categoría de Superintente. En la Gobernación de Guatemala se conservaron las alcaldías mayores y los corregimientos. Ese año se instauró el sistema en el Reino de Chile. En lo que hoy es Ecuador se dieron en Quito (1783) y Cuenca (1786). Las últimas en crearse fueron las de Puerto Príncipe y Santiago, en Cuba, y la de Puerto Rico, en 1813. Los intendentes tuvieron atribuciones en las áreas de hacienda, gobierno y policía, justicia, guerra y patronato (Iglesia), en una búsqueda de mayor control centralizado y efectividad. La opinión general es que el nuevo sistema no redundó en el en el mejor desarrollo de Hispanoamérica. ${ }^{7}$

Todo el cuerpo de reformas -especialmente la aplicación del sistema de intendencias- supuso un grave retroceso en la participación criolla en los altos cargos de gobierno y administración. Después de 1760 se produjo lo que se puede calificar de una creciente "desamericanización” del Estado y del sistema colonial, tanto en lo político como en lo económico y religioso. Funcionarios y empresarios de origen peninsular invadieron espacios que habían sido criollos por mucho tiempo. Así pues, las reformas borbónicas tuvieron el efecto de enajenar a los grupos medios y altos criollos, que vieron como les arrebataban campos y oportunidades que consideraban suyos. En otras palabras, sin proponérselo, la metrópoli contribuyó a agravar las tensiones entre los sectores urbanos, especialmente en las capitales de los diversos reinos americanos.

Por supuesto, las nociones de identidad nacional o regional no iban más allá de los “españoles americanos” urbanos educados. El concepto de patria significaba poco para las llamadas castas en las ciudades, y menos aún para los campesinos (indígenas o 


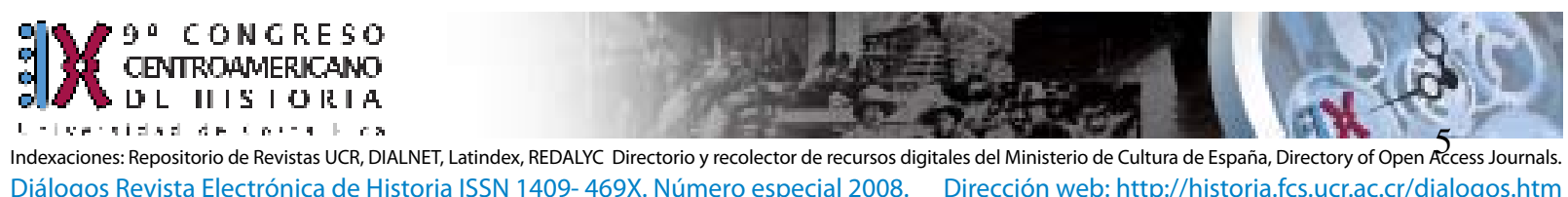

no indígenas) así como para la población de origen africano (libres o esclavos). Las reformas borbónicas supusieron logros importantes, pero estuvieron lejos de restaurar la grandeza imperial de España, así como detener su caída como potencia europea, que era lo que se deseaba.

No todas las reformas alcanzaron sus objetivos, pero tampoco fueron un fracaso. Es innegable que creció el comercio trasatlántico entre España y sus territorios de ultramar, se elevó la recaudación fiscal y se logró estimular la minería de la plata, tanto en México como en Perú.

\section{El sentido urbano del sistema colonial ${ }^{8}$}

Desde un principio, el sistema colonial hispanoamericano resultó desequilibrado. El centro de los poderes -políticos, económicos, culturales y religiosos- estuvo en las capitales (ya fueran costeras y portuarias o interiores), una para cada región. En las ciudades se concentró la población española y toda aquella que la servía (esclavos, mestizos, artesanos, indígenas, comerciantes, etc.). En las capitales de región se encontraban las instituciones centrales, con los funcionarios reales y la jerarquía eclesiástica, así como los mayores conventos de las órdenes religiosas. Cada centro urbano generó empresas mercantiles e instituciones educativas (colegios menores, mayores y universidades) para la educación de la juventud española y criolla. Había pues una acentuada centralización, frente a la múltiple dispersión local de los pueblos de indios, con unas cuantas cabeceras de corregimiento o alcaldía mayor.

La capital (de cada virreinato o reino) era la ciudad en la que residía el máximo representante del monarca y tenía su sede la audiencia. Su área inmediata de influencia incluía las haciendas, labores y estancias de los españoles. A continuación estaban las urbes que eran cabeceras de corregimientos y alcaldías mayores, donde residía el funcionario a cargo de cada circunscripción. Desde ese centro urbano -el más importante para cada región- se ejercía el control sobre todos y cada uno de los pueblos de indios.

En el esquema ideal (raras veces cumplido) no debía de existir población dispersa, salvo la que residía como fuerza laboral en las explotaciones agrícolas y mineras. Pero fue imposible evitar esa población esparcida por “campos y montes”, no sólo indígena sino mestiza o ladina y de origen africano. Permanentemente se mantuvo el esfuerzo por recogerla en el pueblo a que pertenecía, o congregarla en nuevos poblados o villas, aunque no existió una política definida al respeto. ${ }^{9}$

Tanto para fines hacendarios, como religiosos y de gobierno secular, el sistema colonial estaba diseñado para que funcionara a través de la concatenación de los diversos niveles urbanos. Los indios no podían avecindarse en otros pueblos, cada poblado constituía una "comunidad cerrada”. Aunque el sistema se concibió al inicio de la Colonia, después hubo pocas transformaciones. Por la crisis demográfica al principio no hubo necesidad de nuevos pueblos de indios, sino al contrario, juntar la población de los pueblos “perdidos”. Sólo hasta el siglo XVIII (al menos en Guatemala) se congregó población ladina dispersa en nuevas villas, que siguieron la traza reticular tradicional. En buena medida ello fue reflejo de la orientación de la época de racionalizar el sistema y hacerlo más funcional.

\section{Fundaciones en el Reino de Guatemala durante el siglo XVIII}

A) Fundaciones para españoles y ladinos 


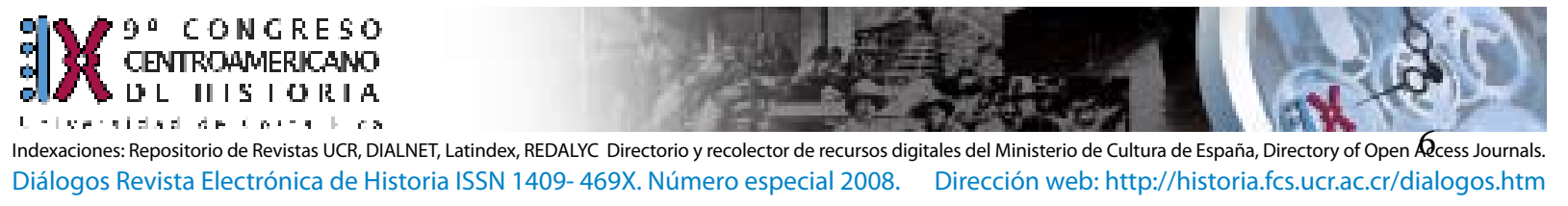

El crecimiento de la población mestiza o ladina obligó a realizar algunas fundaciones o congregaciones de "villas", lo cual, como cosa excepcional, se había iniciado desde el siglo XVII, por ejemplo la Villa de La Gomera (c. 1611), en la Alcaldía Mayor de Escuintla, con población negra y mulata, y el de la Villa de San Vicente de Lorenzana o de Austria, en 1635, en la actual República de El Salvador. ${ }^{10}$

Hasta donde he podido localizar, el primero en fundarse en el siglo XVIII fue el poblado de ladinos de Don García, en 1708, en la Alcaldía Mayor de Escuintla (hoy municipio de La Democracia). Se hizo en una estancia que había sido del Alférez Mayor Don García de Aguilar (por eso el nombre). También a principios del mismo siglo (aunque se desconoce el año exacto) es probable que se estableciera formalmente el poblado de La Ermita (el nombre indicaría su posible origen alrededor de una pequeña iglesia), en el noreste del valle de la actual ciudad de Guatemala. Hay que citar, asimismo, la fundación de la Villa de Rivas, en Nicaragua, alrededor de 1717, en la que se juntaron unas 500 familias (alrededor de 2,400 personas) de no indígenas, al que el Presidente Francisco Rodríguez de Rivas (de ahí su nombre) le otorgó en 1720 el "título y privilegio de villa”. En Costa Rica se mencionan, hacia 1719, los casos de Barba, Aserrí y Esparza, con pocas familias, y en el Valle Central las villas que después serían Heredia (en Cubuquí) y San José.

A partir de 1760 hubo más fundaciones de villas. El primer caso es doble; es decir, tanto de un pueblo de indios como de una villa de ladinos, ya que fue resultado de la inundación ocurrida en San Miguel Petapa, en 1762. El año siguiente se establecieron sendos poblados separados; en el primero se trasladaron los indígenas, en el paraje de La Horca, dos kilómetros al oeste del abandonado, los días 10 y 11 de abril de 1763, mientras los no indígenas se establecieron cuatro kilómetros al oeste en lo que se llamó Villa Nueva de la Concepción (hoy Villa Nueva), cuya traza se hizo el 17 del mismo mes y año. En ambos casos se aplicó al modelo reticular con plaza central, sólo que en Villa Nueva las calles y la plaza fueron mayores.

En la década siguiente se efectuó la congregación de dos "gremios” de ladinos o “valles”, a cargo del Alcalde Mayor de Totonicapán y Huehuetenango: San Luis Salcajá (entre el 9 y el 12 de diciembre de 1776), con 76 familias, y San Carlos Sija (el 14 del mismo mes y año), 70 familias; en ambos casos había un pequeño templo que sirvió de centro urbanístico de referencia. ${ }^{11}$

\section{B) El caso de la destrucción y traslado de Santiago de Guatemala}

En el Reino de Guatemala se produjo un caso excepcional durante la Colonia: el traslado de una capital de 35,000 habitantes, como resultado de los Terremotos de Santa Marta, el 29 de julio de 1773. No era la primera vez que Santiago de Guatemala era afectada por fuertes sismos. Sólo en el siglo XVIII habían ocurrido en 1717 y 1751. Sin embargo, en este caso, por decisión del Presidente Martín de Mayorga (recién llegado a su cargo, ya que había tomado posesión el 12 de junio de ese año) se decidió el abandono e inmediato traslado provisional de la ciudad, en sesiones de principios de agosto. $^{12}$

No es posible ni necesario entrar a referirnos a la conocida polémica que se produjo entre los “terronistas", que se oponían a dejar la ciudad, encabezados por el Arzobispo Pedro Cortés y Larraz, y los “traslacionistas”, comandados por el Presidente. El hecho es que la Corona aprobó el traslado de la capital al Valle de la Ermita o de La Vírgen, por real cédula de 17 de julio de 1775, que se obedeció el 1 de diciembre del mismo año. El primer cabildo en el nuevo asiento se efectuó, en condiciones muy precarias, el 2 de enero de 1776. 


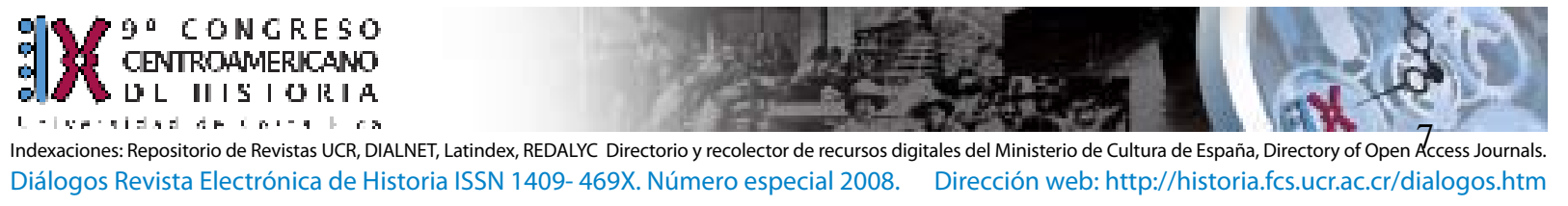

El trazo urbanístico de la nueva ciudad se puede dividir en dos etapas. La primera, inmediata al traslado, estuvo a cargo del Ingeniero Militar y Brigadier Luis Diez Navarro (1700?-1780), nacido en Málaga, quien había llegado al Reino en 1741, desde la Nueva España. Él hizo el primer proyecto (fechado el 31 de enero de 1776), que se puso en ejecución de inmediato, sin esperar la aprobación. Siguiendo las Leyes de Indias y la práctica americana, fue reticular, con calles orientadas a los puntos cardinales, que eran más anchas que las de Panchoy, así como una plaza mayor que casi doblaba el tamaño de la de Santiago, y cuatro plazas menores en los centros aproximados de los barrios. La segunda etapa corresponde al arquitecto español enviado expresamente desde Madrid, Marcos Ibánez (nacido en Odón, Teruel, Aragón, alrededor de 1741), quien fue escogido por el Arquitecto Real Francisco de Sabatini. ${ }^{13}$ Cuando llegó a la Nueva Guatemala, el 17 de julio de 1777, encontró que la ciudad ya estaba trazada y la mayoría de los solares repartidos y a medio construir, por lo que no pudo modificar la traza realizada por Díez Navarro ni aplicar los cambios propuestos por Sabatini. ${ }^{14}$ El primer plano conocido de Ibáñez está fechado el 24 de noviembre de 1778, y contiene pocos cambios con respecto al original de Díez Navarro. ${ }^{15}$

Un servicio que fue costoso, problemático y tardado en solucionarse para la urbe fue el abastecimiento de agua, que sólo se pudo traer, a través de acueductos, desde los pueblos de Mixco y Pinula, obras que tuvo a su cargo el fontanero mayor Bernardo Ramírez, las cuales tomaron tiempo en funcionar adecuadamente y que tuvieron un alto costo.

En la traza de la Nueva Guatemala se reflejó poco el pensamiento ilustrado, ya que no hubo cambios en el diseño urbano, puesto que Díez Navarro aplicó lo establecido en la legislación indiana. Lo que sí se produjo es que las edificaciones reales y principales conventos se hicieron en estilo neoclásico, ${ }^{16}$ comenzando por el Real Palacio, los edificios de correos y aduana, el Real Cabildo, así como la Catedral y Palacio Arzobispal, en la plaza mayor, en cuyo centro se colocó una fuente con una estatua ecuestre de Carlos III, la cual diseñó el sobrestante Bernasconi.

También se incluyeron en el traslado al nuevo asiento los pueblos y aldeas aledaños a Santiago en Panchoy (los principales eran Jocotenango, Almolonga o Ciudad Vieja y San Pedro Las Huertas), cuya traza estuvo a cargo del más prestigioso arquitecto local, Bernardo Ramírez. Asimismo, se recogió población no indígena dispersa y se fundó una nueva población, la Villa de Guadalupe, al sur de la urbe. Todos estos poblados fueron absorbidos a lo largo del siglo XX por la ciudad de Guatemala.

\section{Principales manifestaciones de la Ilustración en el Reino de Guatemala}

Ya hemos tratado a las transformaciones pólítico-administrativas (intendencias) y hacendarias en el Reino. Ahora me referiré a lo propiamente cultural, artístico, social y económico, tanto en la Nueva Guatemala como en todo el Reino. ${ }^{17}$

\section{A ) Las expresiones culturales}

El espíritu ilustrado provino en Guatemala de diversas fuentes e instituciones. Por un lado, llegaban, especialmente a la capital, las obras publicadas en España, incluso algunas condenadas por la inquisición. Uno de sus focos fue la Universidad de San Carlos (la única del reino), donde se había efectuado una reforma y se enseñaba la física experimental desde 1789, gracias al interés y labor de fray Antonio de Liendo y Goicoechea. ${ }^{18}$ Sobre el plan de reformas docentes promovidas en 1782 por este ilustre franciscano nacido en Cartago (Costa Rica), escribió John Tate Lanning: 


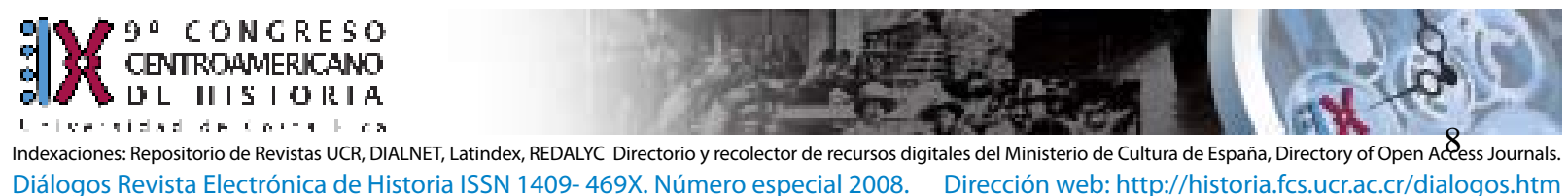

"Lo que Goicoechea recomendaba para Guatemala eran precisamente los grandes trabajos de filosofía natural en boga en España, Francia, Italia, Alemania e Inglaterra durante el siglo XVIII. Dificilmente hubiera podido estar más al día”, ${ }^{19}$

El historiador de la universidad colonial guatemalteca, José Mata Gavidia, se refirió (desde 1948), con base en las tesis universitarias, a la modernización universitaria. ${ }^{20}$ El recién citado Lanning lo expresó de esta manera:

"Los estudiantes de Guatemala tenían en 1785 una amplia, variada y adecuada perceptividad de los problemas del mundo del conocimiento, mayor de lo que cualquier científico experimentado en la enseñanza puede esperar de los estudiantes avanzados de hoy. Desde la duda metódica de Descartes, o la gravitación universal de Sir Isaac Newton, hasta los experimentos de Franklin sobre electricidad, o los últimos avances de la hidráulica; apenas había una cuestión que no fuera defendida o analizada en algún examen de la Universidad de San Carlos de Guatemala en la última mitad del siglo XVIII". ${ }^{21}$

Sin embargo, fue en la Sociedad Económica de Amigos (o Amantes) del País (o de la Patria) donde mejor se aglutinó el grupo de ilustrados y expresó sus inquietudes y afanes de modernización. Surgió en la capital del Reino entre agosto y noviembre de 1794 y fue aprobada por real cédula de 21 de octubre de 1795. En su seno se unió la presencia de funcionarios e intelectuales llegados desde fuera del Reino (como el oidor Jacobo de Villaurrutia, el secretario de la Audiencia Alejandro Ramírez, el Ingeniero Josef de Sierra, el grabador y artista Pedro de Garci-Aguirre, el dean Antonio García Redondo y el médico Narciso Esparragosa), así como personajes del reino residentes en la ciudad de Guatemala (como fray Antonio de Liendo y Goicoechea, el médico José de Flores e Ignacio Beteta, impresor y fundador de la Gazeta, de la que fue editor). La Sociedad fue el auténtico foco irradiador de programas ilustrados, como el intento de establecer una Academia de Bellas Artes, que no se autorizó y que se expresó en una Escuela de Dibujo, dirigida por Garci-Aguirre; una Escuela de Matemática y el establecimiento de un Museo de Historia Natural.

Coincidiendo con el arranque de la entidad llegó a Guatemala una extensión de la Real Expedición Botánica a la Nueva España (1787-1803), que estuvo en diferentes regiones del reino entre 1795 y 99, cuyos principales integrantes fueron José Mariaño Moziño y José Longinos Martínez. ${ }^{22}$ Miembros de la Expedición participaron en la organización del Museo, ${ }^{23}$ y Moziño escribió un ensayo sobre el xiquilite y el añil de Guatemala, con notas de Goicoechea. ${ }^{24}$

Además, hay que mencionar el "redescubrimiento" de un sitio arqueológico maya cerca del pueblo de Palenque (hoy en Chiapas, México) en 1784, que entonces se identificaba como "Casas de Piedra”. El año siguiente el Presidente Josef de Estachería ordenó reconocerlo al sobrestante Bernasconi, quien levantó los primeros planos e hizo dibujos. ${ }^{25}$ En 1787 hubo otra expedición encabezada por el Capitán Antonio del Río, quien levantó más planos. De entonces son los dibujos más exactos de Ricardo Almendáriz. ${ }^{26}$ Cabe preguntarse cuáles pudieron haber sido los efectos de este "descubrimiento" entre los sectores ilustrados de la Nueva Guatemala.

El órgano divulgativo y de discusión de los ilustrados fue la Gazeta de Guatemala, publicada a partir de febrero de 1797. La Gazeta se convirtió en el auténtico vocero de la Sociedad y de muchas personas ilustradas deseosas de reformar y mejorar el reino. Baste recordar un texto aparecido en aquel importante órgano divulgativo, que firmó su editor I. Beteta:

"El reino de Guatemala necesita ser descrito...menuda y prolija- 
mente, con toda puntualidad posible. Tratándose de la Nueva España, o del Perú, países de que se tiene una idea ventajosa, bastan pocas líneas para imponer a sus lectores de su estado; pero hablándose de un reino casi desconocido como el de Guatemala, que está tenido en un concepto menos noble, o del cual no se hace el aprecio a que es acreedor, es menester que las cosas más menudas se toquen, y que la descripción sea tan cabal que desengañe a los prevenidos y dé una idea exacta y precisa a los ignorantes". ${ }^{27}$

\section{B) Las manifestaciones sociales}

Un fenómeno que venía al menos desde el siglo XVII era la rivalidad e incluso animosidad entre españoles recién llegados (incluyendo la mayoría de los funcionarios reales) y los españoles originales o "beneméritos", luego llamados criollos. Esta cuestión es evidente en la obra de Francisco Antonio de Fuentes y Guzmán, Recordación Florida, escrita en los últimos años del siglo XVII. Este fue el "arquetipo" de criollo que dio origen al conocido ensayo de Severo Martínez Peláez. ${ }^{28}$ También estudió este proceso, llevándolo hasta la emancipación, el historiador francés André Saint-Lu. ${ }^{29}$ Dicho sentimiento o conciencia se acentuó a finales del siglo XVIII. Por ejemplo, en la Gazeta de Guatemala apareció el siguiente texto, firmado con el seudónimo Guatemalófilo:

"Un criollo por el hecho de nacer en América, parece que hereda la ojeriza, y el mirar de soslayo a todo europeo. Un europeo, por la la casualidad de haber nacido en la metrópoli, se cree con derecho de preeminencia sobre todo criollo: y esta rivalidad odiosa se echa de ver en las cosas serias, en las frívolas, en los asuntos públicos, en los privados, en todo aquello en que intervienen criollos y europeos. Unos y otros desprecian todo lo que no es del país en que nacieron, se desprecian entre sí, y creen que es amor verdadero de la patria lo que no es más que un amor tonto de ellos mismos”. ${ }^{30}$

Acerca del problema que representaba para la prosperidad del reino el enfrentamiento entre españoles europeos y españoles americanos, se había publicado ya antes en la Gazeta, perspicazmente aunque con pesimismo, este otro texto anónimo:

"Una de las causas de que no prospere este país, de que ningún pensamiento útil florezca, de que ninguna empresa patriótica surta los efectos favorables que surtiría en otra parte, es el espíritu de partido que reina entre europeos y criollos... Hay pandillas, hay bandos, hay secretas parcialidades, no menos funestas al bien público que las de los antiguos Güelfos y Gibelinos en la Italia”, ${ }^{31}$

En la afirmación del sentimiento criollo, a partir de la segunda mitad del XVIII, desempeñó un papel importante la reacción de los americanos ilustrados ante el menosprecio y desconocimiento que se evidenciaba en Europa en las obras del holandés Cornelius de Pauw; de los franceses George Louis Lecrerc, conde de Buffon, Guillaume Raynal y Nicolás Masson de Morvilliers, o el inglés William Roberston, paradógica y precisamente también autores ilustrados. ${ }^{32}$

No debe olvidarse que previamente a la Sociedad Económica se había autorizado el Real Consulado de Comercio (11 de diciembre de 1793), que reunió a los grandes y 


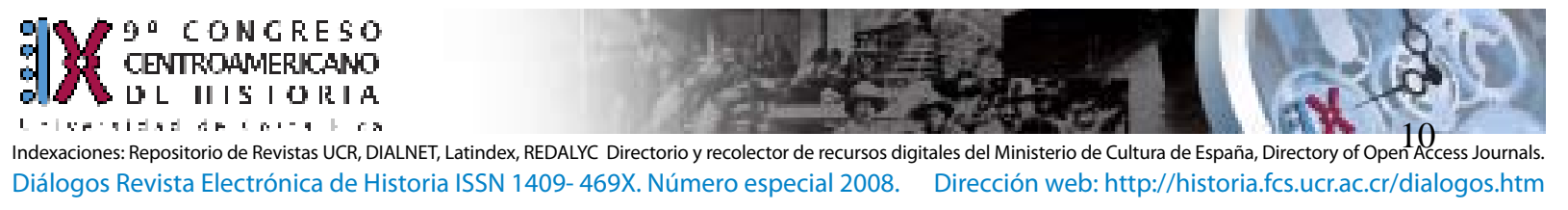

medianos comerciantes y que también participó el espíritu ilustrado. Ambas entidades compartieron miembros, aunque a veces tuvieron criterios diferentes. A ese respecto vale la pena apreciar el pensamiento del sector mercantil sobre la situación del reino, expresado en los Apuntamientos sobre la agricultura y comercio, aunque sea de años después (1810), que prepararon a petición del Diputado por la Nueva Guatemala a las Cortes Generales Españolas. ${ }^{33}$ El gremio mercantil había prosperado mucho con el auge del comercio de finales del siglo XVIII, en el que destacaron varios peninsulares de origen vasco y navarro, como Juan Fermín de Aycinena, ${ }^{34}$ (el primer marqués de Aycinena, único título que hubo en el reino) o Juan Bautista de Irisarri. ${ }^{35}$

En este proceso no puede dejarse de mencionar el rol que tuvo en el pensamiento ilustrado de la Nueva Guatemala la francmasonería. Se trata de un tema apenas estudiado, pero como me ha señalado el colega John Browning, hay poca duda de que hubo masones en la capital y que el exitoso comerciante Juan Bautista de Irisarri (17551805), de origen navarro, desempeñó un papel esencial e innegable, siendo probable que en su casa de habitación se llevaran a cabo las tenidas. ${ }^{36}$ Don Juan Bautista fue, por cierto, un asiduo y agudo colaborador de la Gazeta.

En resumen, nunca antes se había dado en la ciudad de Guatemala ni en todo el Reino un clima similar de discusión y de buscar resolver los problemas que se consideraba obstaculizaban el progreso de la región, como el que se dio en la última década del siglo XVIII. Sin embargo, la reacción en contra de la Ilustración en España comenzó a cambiar las cosas. Se manifestó en la supresión de la Sociedad Económica, en 1800. De cualquier manera, no hay duda que la Ilustración fortaleció la conciencia americana local en el Reino de Guatemala, especialmente en la capital, pero no hay que olvidar que ello únicamente ocurrió en una muy selecta minoría.

\section{La polarización ideológica}

La hipótesis que propongo es que la Ilustración produjo, en todas las partes donde se manifestó (especialmente en España y la América española), la apertura de un proceso que modificó profundamente la composición y las creencias de los sectores medios y altos educados.Terminó la relativa homogeneidad de valores, creencias y propósitos de los sectores dirigentes. Esta "homogeneidad” era aún mayor en España y la América española, exclusivamente católicas y con un estricto control ideológico de varios siglos. Dicho proceso fue producto de una amplia serie de factores, entre los que deben incluirse como esenciales aspectos intimamente ligados con el espíritu ilustrado: ampliación de la educación, el surgimiento de nuevos conceptos políticos contrarios al absolutismo, los afanes de libertad (sobre todo en lo político y lo religioso), la fuerte convicción de que la sociedad debía de ser urgentemente reformada aplicando la ciencia y la razón, la promoción de la tolerancia entre las personas educadas, y el desafío a la autoridad religiosa. Uno de sus resultados fue que provocó primero un alejamiento y después un rompimiento entre el pequeño núcleo de personas ilustradas, seguidores de las nuevas ideas y el resto de la población (incluso la educada y urbana), que se mantuvo, en diversos grados, fiel a los valores tradicionales. Por supuesto, hubo personas que buscaron posiciones intermedias, pero fueron desbordados por el creciente fanatismo e intolerancia de los dirigentes de ambas tendencias.

En otras palabras, mi propuesta es que la Ilustración tuvo un efecto (al menos en la península y en Hispanoamaérica) de largo plazo que sentó las raíces para los conflictos que se generaron después, a lo largo del siglo XIX e incluso del XX. ${ }^{37}$ Ese alejamiento y profunda polarización fueron fundamentales para impedir un concenso político, ideológico y legal, que permitiera una evolución ordenada. Ello provino, en 


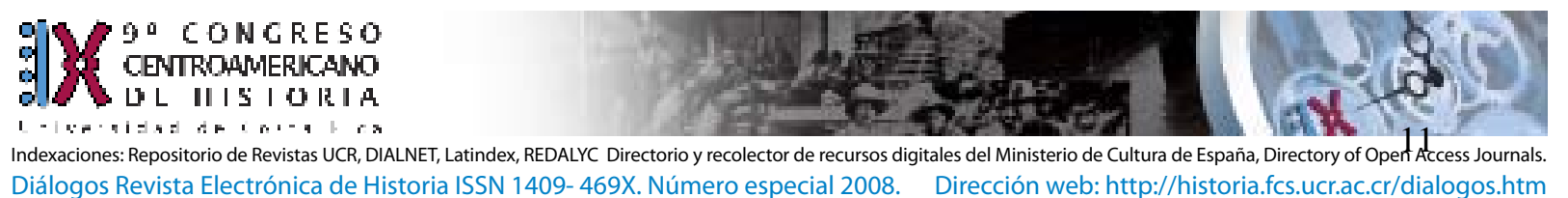

parte, de los antecedentes autoritarios y de intolerancia de la sociedad colonial. Lo que predominó fue el desprecio y la intolerancia entre las diversas corrientes. La convivencia respetuosa se hizo imposible y sólo se resolvía, temporalmente, con la derrota de los contrarios, que a su vez buscaban la revancha, que llegaba en unos años. Con ello se produjo una especie de círculo vicioso de intolerancia y autoritarismo, tanto entre los liberales como entre los conservadores.

Sólo muy lenta y trabajosamente, ya avanzada la vida independiente (en algunos casos hasta mediado el siglo XX), se fue superando esa postura obstinada e irreconciliable. Algunos tradicionalistas moderaron sus posiciones intransigentes, y los modernistas aprendieron la lección de que era imposible imponer cambios que no entendía, quería, ni aceptaba la mayoría de la población. Se trataba de cambios demasiado profundos, que iban en contra de una tradición secular y de lo que postulaba la Iglesia católica.

Mi hipótesis es que el enfrentamiento que caracterizó la vida republicana en toda Hispanoamérica tuvo, en parte, sus raíces en la Ilustración, en el sentido que surgió una minoría con ideas modernas pero importadas e impopulares, que provocaron el rechazo en los sectores tradicionalistas, comenzando por las elites económicas y la Iglesia católica, pero que tuvieron eco entre la población general no educada, tanto urbana como campesina. La obstinacion de los dos bandos principales, encabezados por dirigentes igualmente intransigentes, hizo imposible la contemporización y la búsqueda negociada de soluciones intermedias dentro del marco de la legalidad. Existía un sector educado moderado, quizás mayoritario a ese nivel, pero sin el entusiasmo fanático de los extremistas (de ambos polos), el cual se vio desbordado por los acontecimientos.

\section{Conclusiones y cierre}

La Ilustración llegó a Hispanoamérica en general y al Reino de Guatemala en particular con algún retraso. En realidad, durante las primeras tres décadas del siglo XVIII se produjeron reformas administrativas y cambios económicos que más bien correspondían a la presencia de la nueva dinastía borbónica que al espíritu ilustrado. La Ilustración propiamente se manifestó más en la segunda mitad, sobre todo a partir de la década de 1760. Hubo iniciativas provenientes de la política oficial de reforma, características del llamado despotismo ilustrado. Sin embargo, también los sectores educados urbanos, especialmente de la capital del reino, estaban más o menos al día de la literatura que aparecía en Europa, incluso de aquella que era condenada en las listas inquisitoriales. Esas minorías leían en francés e inglés y recibían libros, ya fuera por medios legales o de contrabando.

Es una exageración y una simplificación decir que las ideas y la literatura ilustrada se difundieron ampliamente en Hispanoamérica. Está más cerca de la verdad afirmar que esa difusión se dio exclusivamente entre los más inquietos espíritus urbanos, que, por supuesto, eran una ínfima minoría. La gran mayoría de la población, incluso de las grandes ciudades hispanoamericanas, no puede considerársele como ilustrada. Sin embargo, entre esos pocos caló hondo su entusiasmo por el racionalismo y el afán de reforma, e incluso en temas religiosos (como la tolerancia y la libertad de cultos y de pensamiento), pero lo hicieron con suma cautela y se abstuvieron de expresarlos públicamente, limitándose a las reducidas tertulias de gente de confianza.

Así pues, como bien escribió en 1970 André Saint-Lu, el aspecto progresista de los ilustrados guatemaltecos no se debe ni sobrestimar ni minimizar. Tuvo una diversidad de manifestaciones, aunque sus expresiones tuvieron una eficacia limitada. Por supuesto, se dio, más o menos simultáneamente, en toda Hispanoamérica y, en el 


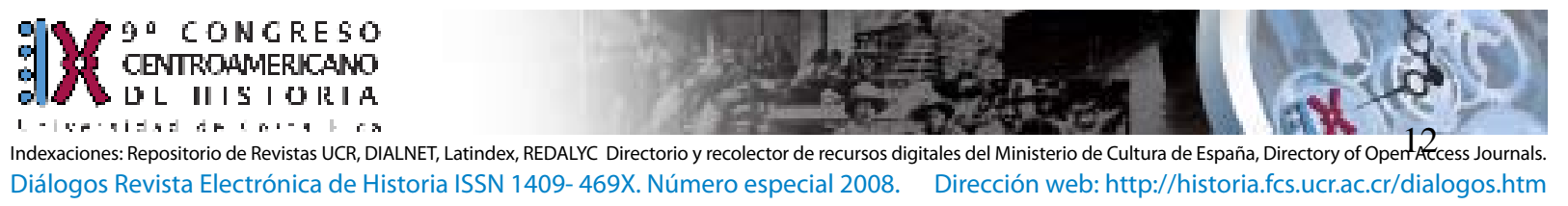

caso de los ilustrados guatemalteca no se manifestó inicialmente en lo político, sino casi sólo en lo académico y en la ciencia. ${ }^{38}$

Si bien no hay duda de que la Nueva Guatemala se construyó dentro del nuevo estilo neoclásico (especialmente los edificios reales), en medio del rechazo de las "deformidades" del anterior estilo (al que luego se llamaría barroco), ${ }^{39}$ hay que reconocer que la traza urbana no fue diferente. Se hizo, de acuerdo a las Leyes de Indias, en forma reticular, con calles orientadas de norte a sur y de oriente a poniente, con una gran plaza central y cuatro plazas menores en los cuadrantes de los barrios. Eso sí, las manzanas fueron mayores, las calles más anchas y la plaza mayor casi duplicó las dimensiones de la de Santiago de Guatemala. El primer responsable del proyecto urbanístico fue el Ingeniero Luis Díez Navarro. La propuesta se puso en ejecución sin esperar la real revisión y aprobación. Es decir, que fue imposible incorporar las recomendaciones y observaciones que hizo al proyecto F. Sabatini. Así, cuando llegó el arquitecto Marcos Ibáñez, en 1777, poco pudo cambiar, aunque sí se hizo cargo del diseño de los edificios reales, así como de la Catedral y el palacio arzobispal. Además, no duró mucho la presencia de Ibáñez, ya que hacia 1783 retornó a la península. El que sí permaneció fue su sobrestante Antonio Bernasconi, pero sólo dos años fues murió en 1785).

El nuevo clima ideológico y de reforma se desarrolló en un reducido círculo de iniciados, sobre todo a partir de las últimas dos décadas del siglo. Una serie de factores contribuyeron: la reforma universitaria, el inicio de la francmasonería, las expediciones arqueológicas y botánicas, la llegada de funcionarios y personajes ilustrados, las inquitudes intelectuales, las tertulias literarias, las nuevas corrientes artísticas y de pensamiento, etcétera. Ese clima fructificó en la fundación de la Sociedad Económica de Amantes de la Patria y en la publicación de la segunda época de la Gazeta de Guatemala, un periódico lleno de inquietudes, discusiones e iniciativas genuinamente ilustradas. También se estableció el Real Consulado de Comercio. Todo ello ocurrió en un clima de prosperidad y optimismo, a la vez que se acrecentaba entre los criollos la conciencia nacionalista ciudadana.

Sin embargo, muchas de las reformas exacerbaron el preexistente enfrentamiento entre españoles americanos (criollos) y españoles peninsulares. Los primeros se sintieron discriminados por la mayor presencia de funcionarios de origen peninsular, a la vez que la literatura ilustrada pseudocientífica menospreciaba lo americano. Todo ello se vio interrumpido por la vuelta atrás que supuso el temor de la monarquía española (y también de otros países) ante los excesos que ocurrían en la Francia revolucionaria. La supresión de la Sociedad Económica en 1800 (real cédula de 23 de noviembre de 1799) vino a frustrar todavía más a los criollos educados y a aumentar su conciencia nacional, que poco a poco fue afirmándose.

Se trata, pues, de situaciones y procesos muy complejos, que tuvieron alcance limitado. Empero, no hay duda de que existió ese clima y ambiente ilustrado, aunque fuera en un sector muy minoritario. En la literatura que yo conozco no se enlaza o relaciona el clima ilustrado con el surgimiento de los partidos posteriores, ni que esto fue una situación nueva. Desafortunadamente, algunos de los ilustrados se fanatizaron (un ejemplo extremo sería José F. Barrundia) y una vez conseguida la independencia y planteada la guerra civil, con el triunfo liberal, promovieron las reformas de una manera a la vez entusiasta y urgente, sin medir las reacciones opositoras y sin darse cuenta de las diferencias que había con la realidad de donde se importaban las reformas. ${ }^{40}$

Se trata de un tema que requiere ser puesto a prueba. Espero que en el futuro tenga ocasión de profundizar en mi hipótesis, a fin de comporbarla o desecharla. 


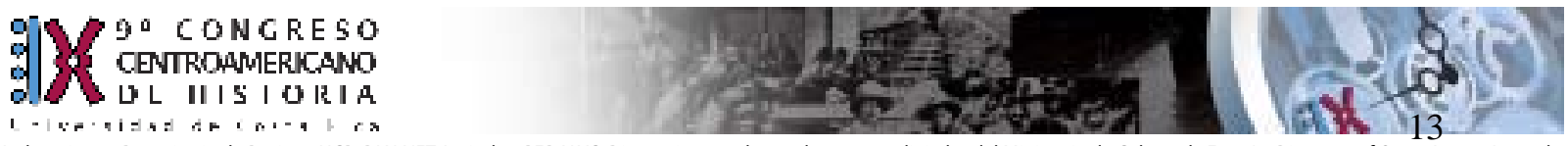

Indexaciones: Repositorio de Revistas UCR, DIALNET, Latindex, REDALYC Directorio y recolector de recursos digitales del Ministerio de Cultura de España, Directory of Open Access Journals. Diálogos Revista Electrónica de Historia ISSN 1409-469X. Número especial 2008. Dirección web: http://historia.fcs.ucr.ac.cr/dialogos.htm

${ }^{1}$ Véase al respecto la última edición del Diccionario de la Lengua Española de la Real Academia Española de la Lengua.

${ }^{2}$ Incluso dentro de algunos círculos eclesiásticos católicos hubo esfuerzos de reforma y hostilidad contra ciertas prácticas de devoción y piedad popular, así como contra algunas manfestaciones de fe, que algunos han lamado modernamente barrocas.

${ }^{3}$ La respuesta de I. Kant fue a la pregunta que formuló, a varios pensadores y políticos, el periódico BerlinerMonatschrift. La respuesta es de 5 de diciembre de 1783. Véase, Carlos Pereda, Razón e incertidumbre (Madrid: Siglo Veintiuno, 1994). Los criterios kantianos de libertad de pensar y de dignidad humana están íntimamente ligados y parten de considerar al hombre como un un fin en sí mismo y no como un medio; por lo tanto, pertenecen a lo más consubstancial del ser humano.

${ }^{4}$ Sobre la existencia de lo que se llama "catolicismo ilustrado" y sus esfuerzos contra la superstición en las prácticas religiosas, véase, Mario Góngora, "La Ilustración, el despotismo ilustrado y las crisis ideológicas en las colonias”; en su, Historia de las ideas en América española y otros ensayos.

Compilación y edición de Óscar Julián Guerrero (Clásicos del Pensamiento Hispanoamericano; s.l.: Editorial Universidad de Antioquia, 2003), 185-186.

${ }^{5}$ Véase, Margarita Eva Rodríguez de García. Compañías privilegiadas de comercio con América y cambio político (Estudios de Historia Económica No 46; Madrid: Banco de España).

6 Jorge Luján Muñoz, “El establecimiento del Estanco del Tabaco en el Reino de Guatemala”. Mesoamérica 41 (junio de 2001), 99-136.

${ }^{7}$ Lillian E. Fischer, The Intendent System in Spanish America (2a ed.; New York: Gordian Press, 1969). Gisela Morazzini de Pérez Enciso, Las intendencias en España y América (Caracas: Universidad Central de Venezuela, 1976). Héctor H. Samayoa G., Implantación del régimen de intendencias en el Reino de Guatemala (Guatemala: José de Pineda Ibarra, 1960). Cristina Zilbermann de Luján, "El Régimen de Intendencias", en, Historia General de Guatemala (de aquí en adelante HGG), Tomo III: Siglo XVIII hasta la Independencia (Guatemala: Asociación de Amigos del País- Fundación para la Cultura y el Desarrollo, 1994), 33-38.

${ }^{8}$ Sobre este tema J. Luján M., "El sentido urbano de la colonización española: el proceso fundacional en el Reino de Guatemala”. Anales de la Academia de Geografía e Historia de Guatemala, 78 (2003), 49-57. ${ }^{9}$ Jorge Luján Muñoz, “Urbanismo”. HGG, Tomo II: Dominación Española: desde la Conquista hasta 1700 (Guatemala: AAP-FCD, 1994), 691-8.

${ }^{10}$ Jorge Luján Muñoz, "Política Fundacional en los Siglos XVI y XVII”, HGG, Tomo II (Guatemala: AAP-FCD, 1994), 131-142.

${ }^{11}$ Para este tema ver: J. Luján Muñoz, "Reducción y fundación de Salcajá y San Carlos Sija (Guatemala) en 1776”, Anales de la Academia de Geografía e Historia de Guatemala, 49 (1976), 45-66; "Las Fundaciones en el Reino de Guatemala”, HGG, Tomo III, 47-56. También mi trabajo, Algunos ejemplos de urbanismo en Guatemala en la última parte del siglo XVIII. (Guatemala: Facultad de Humanidades Sección de Publicaciones, 1978).

${ }^{12}$ Véase, Cristina Zilbermann de Luján, Aspectos socioeconómicos del traslado de la ciudad de Guatemala (1773-1783) (Guatemala: Academia de Geografía e Historia de Guatemala, 1987), y, “Destrucción y Traslado de la Capital. La Nueva Guatemala de la Asunción”, HGG, Tomo III, 199-210.

${ }^{13}$ Con él viajó, como sobrestante, Antonio de Bernasconi, nacido en Ancona (Italia) y también escogido por Sabatini.

${ }^{14}$ Las objeciones de Sabatini eran que los terrenos asignados a los edificios reales en la plaza mayor le parecían insuficientes, también que sólo se hablara de edificios de una planta, que las manzanas de orientaran a los puntos cardinales (él pensaba que era mejor que las esquinas dieran a los puntos cardinales a fin de enfrentar mejor los vientos) y rodear la traza con "una tapia” o muralla.

${ }^{15}$ Jorge Luján Muñoz, “Urbanismo”, HGG, Tomo III, 465-72.

${ }^{16}$ Véase, “Arquitectura: 1780-1821”, HGG, Tomo III, 493-504.

17 Como se ha podido apreciar a lo largo del presente trabajo, es numerosa la literatura histórica que trata de la Ilustración en el Reino de Guatemala que ya ha sido citada o que se citará para cuestiones específicas. Sin embargo, vale la pena mencionar tres obras generales: la de Carlos Meléndez Chaverri, La Ilustración en el antiguo Reino de Guatemala (San José, C.R.: EDUCA, 1970), el ensayo sobre lo artístico de Ricardo Toledo Palomo, Las artes y las ideas de arte durante la I ndependencia (1794-1821) (Publicación Especial 19; Guatemala: Sociedad de Geografía e Historia de Guatemala, 1977) y el reciente trabajo de Sergio García Granados, Libre crezca fecunda. Guatemala en el Siglo de las Luces 1729-1821 (Guatemala: Magna Terra Editores, 2005).

${ }^{18}$ Es interesante que en 1781, fray Fermín Aleas, dominico español recién llegado al reino y catedrático de la Universidad de San Carlos, hizo una denuncia poco fundada a España sobre la mala calidad de la 


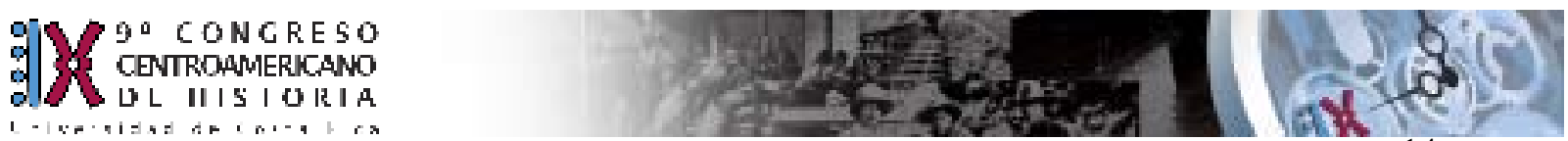

Indexaciones: Repositorio de Revistas UCR, DIALNET, Latindex, REDALYC Directorio y recolector de recursos digitales del Ministerio de Cultura de España, Directory of Op』rAAccess Journals. Diálogos Revista Electrónica de Historia ISSN 1409-469X. Número especial 2008. Dirección web: http://historia.fcs.ucr.ac.cr/dialogos.htm

docencia, que provocó una averiguación y una dura reacción del claustro de San Carlos. Aleas terminó por retractarse y pidió disculpas. S. García Granados, 90-3.

19 J. T. Lanning, The Eighteenth Century Enlightenment in the University of San Carlos de Guatemala (Ithaca, N.Y.: Cornell University Press, 1956), 70. Hay edición en español, Guatemala: Editorial Universitaria, 1978.

${ }^{20}$ J. Mata G. Panorama filosófico de la Universidad de San Carlos al final del siglo XVIII (Guatemala: Unión Tipográfica, 1948).

${ }^{21}$ Lanning, 115.

${ }^{22}$ José de la Sota Ríus, “La Expedición Científica a Nueva España (1787-1803) y al Reino de Guatemala (1795-1799)”, HGG, Tomo III, 621-26.

${ }^{23}$ Noticia del establecimiento del Museo de esta Capital de la Nueva Guatemala y exercicios públicos de Historia Natural que han tenido en la Sala de Estudios de dicho Museo...bajo la dirección de José Longinos Martínez...(Guatemala: Oficina de la Viuda de D. Sebastián de Arévalo, 1797).

${ }^{24}$ José María Moziño, Tratado del Xiquilite y Añil de Guatemala (1799).

${ }^{25}$ Bernasconi murió inesperadamente en octubre de 1785, quizás como consecuencia de su viaje a Palenque.

${ }^{26}$ Véase, Ricardo Castañeda Paganini, Las Ruinas de Palenque, su descubrimiento y primeras exploraciones en el siglo XVIII (Guatemala: Tipografía Nacional, 1946), y, José Alcina Franch, Arqueólogos o anticuarios. Historia antigua de la Arqueología en la América española (Barcelona: Ediciones del Serbal, 1995), cap. 4, "El siglo XVIII y la Ilustración”. También, Paz Cabello, Política investigadora de la época de Carlos III en el área maya. Según documentación de Calderon, Bernasconi, Del Río y otros (Madrid: Ediciones de la Torre, 1992), y, Carlos Navarrete, Palenque, 1784: el inicio de la aventura arqueológica maya (Centro de Estudios Mayas Cuaderno 26 (México, D.F.: UNAM, 2000). ${ }^{27}$ Gazeta de Guatemala, I:14 (1797), 107-8.

${ }^{28}$ La patria del criollo. Ensayo de interpretación de la realidad colonial guatemalteca (1 ${ }^{\mathrm{a}}$. ed., Guatemala: Editorial Universitaria, 1970).

${ }^{29}$ Condition coloniale et consciense creole au Guatemala (Faculté des Lettres et Ciences Humaines de Poitiers; Paris: Presses Universitaire de France, 1970). Edición en español: Condición colonial y conciencia criolla en Guatemala (1524-1821) (Guatemala: Editorial Universitaria, 1978). Véase también del mismo autor, “Españoles y Criollos. Criollismo”, HGG, Tomo III, pp. 225-34.

${ }^{30}$ Gazeta de Guatemala, I:8 (1797), 59-60.

${ }^{31}$ Ibid., I:3 (1797), 17.

${ }^{32}$ Sobre este tema, véanse los artículos de John Browning en el Tomo III de la HGG, "Las Gazetas de Guatemala”, 565-578; "Rafael Landívar: Poeta, Historiador y Revolucionario”, 605-612, y, "El Despertar de la Conciencia Nacional”, 627-640. También Alcina, 58-60 y García Granados, 32-3.

${ }^{33}$ Apuntamientos sobre la Agricultura y Comercio del Reyno de Guatemala que el Señor Don Antonio de Larrazábal Diputado a Cortes Extraordinarias de la Nación por la misma Ciudad, pidió al Real Consulado en Junta de Gobierno de veinte de octubre de 1810 (Guatemala: Imprenta de Manuel de Arévalo, 1811).

${ }^{34}$ Richmond F. Brown, Juan Fermín de Aycinena: Central American Entrepeneur, 1729-1796 (Norman: University of Oklahoma Press, 1997).

${ }^{35}$ John Browning, Vida e ideología de Antonio José de Irisarri (Guatemala: Editorial Universitaria, 1986).

${ }^{36}$ Información personal.

${ }^{37}$ En España incluso se elaboró un concepto muy ilustrativo: “las dos Españas”, que ha levantado interesantes polémicas y objeciones. Véase: Santos Juliá, Historia de las dos Españas (Madrid: Taurus, 2004).

${ }^{38}$ Saint-Lu, Condición colonial, 168-9.

39 “Real Disposición para desterrar las deformidades arquiectónicas de los edificios (1777)”. Publicada por Francisco de la Maza. Anales del Instituto de Investigaciones Estéticas (México), 31 (1962), 144-6. ${ }^{40}$ Sobre este tema véase, Jorge Luján Muñoz, "Del derecho colonial al derecho nacional: el caso de Guatemala”, Jahrbuch für Geschichte Lateinamerikas, 38 (2001), 85-107. 